\title{
EFEITO DE SUBSTRATO ARTIFICIAL NO ENRAIZAMENTO DE ESTACAS DE CALANCHOE (Kalanchoe x blossfeldiana cv. SINGAPUR, CRASSULACEAE)
}

\author{
A.L. GONÇALVES \\ Instituto de Botânica, C.P. 4005, CEP: 04301-970 - São Paulo,SP \\ K. MINAMI \\ Departamento de Horticultura - ESALQUUSP, C.P. 9 - CEP: 13418-900 - Piracicaba,SP
}

RESUMO: Dez misturas artificiais foram estudadas para avaliar o efeito sobre o enraizamento de estacas apicais de Kalanchoe $x$ blossfeldiana cv. Singapur, da familia Crassulaceae. Essas misturas foram as seguintes: vermiculita + casca de arroz tostada nas proporções 1:1, 2:1 e 3:1; vermiculita + torta de filtro Oliver nas proporções 1:1, 2:1 e 3:1; vermiculita + turfa da região de Atibaia-SP, nas proporçōes 1:1, 2:1 e 3:1; vermiculita + casca de pinheiro (mistura comercial). Os melhores resultados foram obtidos com a mistura vermiculita + torta de filtro Oliver em todas as proporções, vermiculita + casca de arroz tostada 3:1 e vermiculita + turfa 3:1. Os piores desempenhos foram os das misturas vermiculita + casca de pinheiro e vermiculita + turfa 1:1.

Descritores: vermiculita, casca de arroz, torta de filtro, enraizamento, calanchoe, Kalanchoe $x$ blossfeldiana.

\section{ARTIFICIAL SUBSTRACT EFFECT ON THE ROOTING OF CALANCHOE (Kalanchoe $x$ blossfeldiane ev. SINGAPUR, CRASSULACEAE) CUTTINGS}

\begin{abstract}
Ten different artificial mixtures were studied as rooting media for Kalanchoe $x$ blossfeldiana cv. Singapur cuttings. They were: vermiculite + toasted rice hulls (1:1, 2:1, 3:1); vermiculite + Oliver filter cake (1:1, 2:1, 3:1); vermiculite + peat $(1: 1,2: 1,3: 1)$; and vermiculite + pine bark (commercial mixture). The best results were observed for vermiculite + Oliver filter cake $(1: 1,2: 1,3: 1)$, vermiculite + toasted rice hulls $(3: 1)$ and vermiculite + peat $(3: 1)$. The worst results were observed with vermiculite + pine bark and vermiculite + peat (1:1).
\end{abstract}

Key Words: Kalanchoe $x$ blossfeldiana, rice hull, Oliver filter cake, vermiculite, rooting, rooting artificial.

\section{INTRODUÇÃO}

Segundo BUNT (1976), a primeira tentativa para produção de substratos artificiais para o cultivo de plantas, seguindo normas técnicas, ocorreu no Instituto de Horticultura John Innes, na Inglaterra, em 1939, e utilizava uma composição à base de solo esterilizado, turfa e areia complementada com doses fixas de superfosfato, sulfato de potássio e carbonato de cálcio.

AIRHART et al (1978), estudando a estrutura da casca de pinheiro curada e moída de duas espécies, Pinus elliotti Engelm, e Pinus taeda L., observaram numerosas aberturas externas, paredes celulares rompidas e conexões internas das células que possibilitam a entrada da água. Já a periderme não possuia poros $\mathrm{e}$ apresentava superfícies rugosas, contendo substâncias cerosas que possivelmente fariam resistências à penetração ou absorção de água, o que explicaria o fato de um substrato com casca de pinheiro exigir mais água do que um com turfa.

MINAMI (1980) faz referências a características que uma mistura artificial deve apresentar para ser utilizada como substrato para enraizamento e cultivo de plantas, relacionando as quantidades máximas de argila, areia e matéria orgânica que podem possuir sem causar problemas.

NOLLAND \& WILLIAMS (1980) estudaram o enraizamento de estacas de Kalanchoe $x$ blossfeldiana $\mathrm{cv}$. Jean em substrato de perlita e de perlita mais turfa em partes iguais, observando que o enraizamento se deu após quatro semanas, com o uso de irrigação por nebulização e que os maiores pesos de matéria fresca foram obtidos com substrato misto.

KOVACIC \& HOLCOMB (1981) fizeram experimentos com calanchoe, utilizando a cultivar Pixie. Partiram de estacas enraizadas em 
substrato, contendo partes iguais de turfa e vermiculita, usando cinco formulações de adubo de solubilidade lenta, aplicadas no plantio e em cobertura. Não encontraram diferenças significativas em altura da planta e peso da matéria fresca, quando cultivadas no sistema de sub-irrigação.

LIMA et al (1986) conduziram experimentos com estaquia de arbustos de folhagem ormamental, onde estudaram o efeito de misturas de vermiculita mais casca de arroz não tostada e de vermiculita mais casca de pinheiro, ambas as misturas com três composições diferentes cada uma, concluindo que os melhores resultados obtidos foram com a mistura de vermiculita e casca de pinheiro.

Visando o enraizamento de orgãos naturais de propagação de espécies omamentais, MINAMI (1986) faz recomendações de uso de uma série de misturas com indicações para as espécies adequadas.

VERDONCK et al (1984) fazem referências ao problema da queda de qualidade dos substratos com alto teor de turfa, principalmente quanto à porosidade e à aeração para as raízes das plantas cultivadas.

No Brasil, JUNG et al (1990) realizaram estudos, visando a determinação da necessidade de calagem em turfas do Município de Viamão, no Rio Grande do Sul, para sua utilização como substrato para plantas. Obtiveram uma correlação positiva, relacionando os valores de $\mathrm{pH}$ estabilizado, com 0 aumento das doses de carbonato de cálcio utilizadas, permitindo estimar a quantidade de $\mathrm{CaCo}$, que se precisa adicionar à turfa, para que o $\mathrm{pH}$ da mesma possa ser elevado a um nível desejado.

$\mathrm{Na}$ França, LEMAIRE et al (1988) estudaram produtos à base de fibras de duas espécies de pinheiro, Pinus pinaster Alt. e Pinus silvestris, L., submetidas a tratamentos de vapor e observaram seu bom desempenho para cultivo de plantas ornamentais em vasos.

$O$ objetivo deste trabalho foi avaliar o efeito de diferentes misturas artificiais no enraizamento de estacas de Kalanchoe $x$ blossfeldiana cv. Singapur.

\section{MATERIAIS E MÉTODOS}

O experimento foi instalado na Seção de Ornamentais do Instituto de Botânica, da Secretaria Estadual do Meio Ambiente, em São Paulo, SP.
O clima local, de acordo com SANTOS \& FUNARI (1976), є do tipo B3B'3rs2a, segundo a classificação de Thornthwaite de 1948.

A temperatura média anual é de 18,5०C, com máxima e mínimas já registradas de $35 \circ \mathrm{C}$ e $-1,2 \circ \mathrm{C}$. A pluviosidade média anual, registrada no período de 1968 a 1977, foi de $1378 \mathrm{~mm}$.

O experimento foi instalado em casa de vegetação, coberta com telhas plásticas transparentes e com paredes feitas de ripas de madeira, apresentando espaços vazios de larguras idênticas à das ripas, de modo a permitir a ventilação do seu interior.

O material utilizado para propagação constou de estacas apicais de calonchoe da cultivar Singapur, obtidas de matrizes cultivadas na Floricultura Araki, situada no Município de Itaquaquecetuba, região da Grande São Paulo.

As matérias primas para confecção das misturas artificiais para uso como substrato foram: casca de arroz tostada, torta de filtro Oliver, turfa da região de Atibaia-SP e vermiculita de diâmetro fino. Com esses materiais foram feitas combinações diferentes que resultaram nos seguintes tratamentos abaixo:

- vermiculita + casca de arroz tostada nas proporções 1:1, 2:1, 3:1;

- vermiculita + torta de filtro Oliver nas proporções 1:1, 2:1, 3:1;

- vermiculita + turfa nas proporções 1:1, 2:1, 3:1;

- vermiculita + casca de pinheiro - mistura comercial.

O delineamento estatístico utilizado foi o inteiramente casualizado com 10 tratamentos e 5 repetições.

As estacas de calanchoe mediam $5 \mathrm{~cm}$ de comprimento e ostentavam 3 pares de folhas mais a gema apical. Foram retiradas com uso de canivete afiado e plantadas em canteiros de isopor suspensos, contendo células de $3 \times 3 \times 6 \mathrm{~cm}^{3} \mathrm{e}$ orifício de drenagem de $1 \mathrm{~cm}^{2}$. As células foram preenchidas com as misturas já referidas, as quais foram acrescidas de doses de calcário dolomítico correspondente a $3 \mathrm{~kg} / \mathrm{m}^{3}$.

As estacas foram plantadas a $2 \mathrm{~cm}$ de profundidade, de modo que o nó inferior ficasse enterrado $e$ as folhas mantidas intactas.

Foram, a seguir, colocadas na casa de vegetação até o momento da avaliação do sistema radicular. Durante esse período, foram feitas irriga- 
cões dírias, a princípio uma, e depois duas vezes ao dia, diretamente no substrato, sem molhar as folhas. Utilizou-se de um regador manual plástico, dotado de crivo fino. Não ocorreram doenças ou ataque de pragas.

Decorridos trinta dias após o plantio, as mudas foram retiradas das células e o seu sistema radicular foi avaliado, através de notas conforme o seguinte critério:

nota 1 - nenhum vestígio de iniciação radicular;

nota 2 - pequenas protuberancias indicando formação radicular e/ou algumas pequenas raízes no caule cicatricial;

nota 3 - as mudas apresentavam razoável formação de raízes no caule cicatricial e primórdios de raízes no nó enterrado;

nota 4 - as mudas apresentavam boa formação de raízes originárias de calo cicatricial com ate $3 \mathrm{~cm}$ de comprimento e também rázes no nó enterrado no substrato, estes, com aproximadamente $1 \mathrm{~cm}$ de comprimento, havendo também primórdios de rázes no entre-nó.

nota 5 - o sistema radicular formado era abundante e vigoroso, havendo raízes no colo cicatricial, com ate $5 \mathrm{~cm}$ de comprimento, bem como raízes formadas no nó enterrado e também no entre-nó.

A nota atribuída a cada parcela foi a média aritmética das notas atribuídas a cada uma das 4 plantas da parcela.

\section{RESULTADOS E DISCUSSÃo}

Os resultados obtidos com relação ao enraizamento constam da TABELA 1.

Interpretando o comportamento das misturas que apresentaram os melhores resultados em relação ao enraizamento notam-se dois fatos: o primeiro é que neles estão todas as misturas de vermiculita com torta de filtro Oliver; o segundo, que estão também inclusas as misturas contendo 75\% de vermiculita em relação ao outro componente.

Com relação às misturas com torta de filtro Oliver, convém ressaltar a sua riqueza em nutrientes, conforme é demonstrado por KIEHL (1985). Em todas as proporções da mistura com vermiculita, era notório o grande desenvolvimento de raizes, tanto no sentido de comprimento como de volume. $O$ enraizamento ocorreu em toda a extensão da haste, incluindo a parte terminal, os nós e os entre-nós. Essa abundante formação de raízes parece reflexo da disponibilidade de cálcio nas misturas, somada à aplicação de calcário dolomítico, pois, segundo EPSTEIN (1975), as raízes das plantas são particularmente sensíveis a esse elemento.

Já para o segundo fato, ou seja, os tratamentos com maior proporção de vermiculita, pode-se creditar o desempenho às excelentes qualidades da vermiculita para enraizamento de estacas conforme diversos autores, entre eles MINAMI (1980) e SALES (1982). Assim, parece ocorrer uma certa compensação entre a menor disponibilidade de nutrientes $e$ as excelentes propriedades físicas da vermiculita, principalmente a sua grande capacidade de aeração, aliada a boa capacidade de retenção de água.

Nas misturas que propiciaram os niveis intermediários de enraizamento, notou-se como característica comum a todos: a diminuição da participação da vermiculita em volume de mistura, sendo os resultados menos expressivos quando a proporção era de $1: 1$, ou seja, a casca de arroz e a turfa constituiam $50 \%$ do volume total do substrato, sendo o pior resultado o da mistura com o da turfa.

O desempenho mais fraco, coube à mistura vermiculita-casca de pinheiro, em proporção não especificada, cujas estacas apresentaram péqueno volume de ráizes, estas apresentando comprimento pequeno com primórdios de raízes nos nós e sem formação de raízes nos entre-nós.

Além disso, as estacas não apresentaram sinais de desenvolvimento, parecendo terem apenas emitido raízes, sem estarem absorvendo os nutrientes.

Uma das explicações para o fato da má performance pode ser encontrada no tipo de vermiculita utilizado para a confecção da mistura. Em vez do uso vermiculita hortícola ou seja, um material com granulação compreendida no tipo denominado fino, a granulação usada aparentemente pertencia ao grupo micron, ou seja, com partícula de diâmetro inferior a $0,5 \mathrm{~mm}$. Nesta composição, o particulamento $\epsilon$ muito grande e a densidade da vermiculita atinge a $140 \mathrm{~kg} / \mathrm{m}^{3}$; com um teor de alumínio de $10 \%$ na composição. Tal particulamento deve dar origem a grande quantidade de alumínio livre ou metálico nesse substrato. 
TABELA 1 - Médias de notas de enraizamento de estacas de Kalanchoe $x$ blosfeldiana Poell cv. Singapur em misturas artificiais.

\begin{tabular}{lc}
\hline \multicolumn{1}{c}{ Tratamentos } & Medias \\
\hline vermiculita + casca de arroz tostada 1:1 & $4,10 \mathrm{c}$ \\
vermiculita + casca de arroz tostada $2: 1$ & $4,50 \mathrm{~b}$ \\
vermiculita + casca de arroz tostada 3:1 & $5,00 \mathrm{a}$ \\
vermiculita + torta de filtro Oliver 1:1 & $5,00 \mathrm{a}$ \\
vermiculita + torta de filtro Oliver 2:1 & $5,00 \mathrm{a}$ \\
vermiculita + torta de filtro Oliver 3:1 & $5,00 \mathrm{a}$ \\
vermiculita + turfa 1:1 & $3,45 \mathrm{~d}$ \\
vermiculita + turfa 2:1 & $4,10 \mathrm{c}$ \\
vermiculita + turfa 3:1 & $5,00 \mathrm{a}$ \\
vermiculita + casca de pinheiro & $3,00 \mathrm{e}$ \\
\hline F & $331,64 * *$ \\
Coeficiente de variação (\%) & 2,04 \\
\hline \hline
\end{tabular}

** = significativo ao nível de $1 \%$ de probabilidade; médias acompanhadas da mesma letra não diferem ao nivel de $5 \%$ de probabilidade pelo Teste de Tukey.

Conforme HAAG \& SARRUGE (1971), não há evidências de que o alumínio seja um elemento essencial; pelo contrário, para certas espécies, ele é tóxico e os sintomas surgem primeiramente no sistema radicular, inclusive levando até à morte das raízes.

Outro aspecto é ressaltado por AIRHART et al (1978), que comentam que a epiderme da casca de pinus possui poros e apresenta substâncias cerosas que oferecem resistência à penetração ou absorção de água. Essas cascas aliadas à vermiculita de pequena dimensão, que também não possui estrutura capaz de reter umidade, criam condições desfavoráveis ao enraizamento das estacas.

0 uso de vermiculita hortícola em mistura com casca de pinheiro, evitando o pó e as partículas acima de $5 \mathrm{~mm}$, através de peneiramento e ventilação, com grande probabilidade apresentaria melhor performance que a mistura comercial utilizada neste estudo.

\section{CONCLUSÓES}

1 As melhores misturas para enraizamento de estacas de calanchoe (Kalanchoe $x$ blossfeldiana cv. Singapur, Crassulaceae) são de vermiculita + torta de filtro Oliver, nas proporções em volume de 1:1, 2:1 e 3:1 e de vermiculita + casca de arroz tostada 3:1.

2. Também apresentaram bons resultados, as misturas vermiculita/casca de arroz nas proporcões de 2:1 e $1: 1$ e vermiculita + turfa 2:1.

3. Os piores desempenhos couberam as misturas vermiculita + casca de pinheiro e vermiculita + turfa 1:1.

\section{REFERENCIAS BIBLIOGRÁFICAS}

AIRHART, D.L.; MATARELLA, N.J.; POKORNY, F.A. Structure of processed pine bark. Joumal of the American Society Horticultural Science Alexandria, v.103, p.3, p.404, 1978. 
BUNT, A.C. Modern potting composts. London, George Allen \& Unwin, 1976. 277p.

EPSTEIN, M. Nutrição mineral e plantas: principios e perspectivas. São Paulo: EDUSP, 1975. 341p.

HAAG, H.P.; SARRUGE, J.R. Nutrichăo Mineral das Plantas. Piracicaba: ESALQ, Departamento de Química, 1971. 187p.

JUNG, M.; KAMPF, A.N.; BACKES, M.A. Determinação da necessidade de calagem em turfas do Município de Viamāo,RS. In: CONGRESSO BRASILEIRO DE FLORICULTURA E PLANTAS DANINHAS ORNAMENTAIS, 6., Campinas, 1987. Anais... Campinas: Sociedade Brasileira de Floricultura e Plantas Ornamentais, 1990, p.192-205.

KIEHL, E.J. Fertilizantes Organicos. São Paulo: Ed. Agronomica Ceres, 1985. 492p.

KOVACIC, M.T.; HOLCOMB. J. Effects of controlledrealese fertilizers and application methods on growth and leaf elements; concentration of Kalanchoe blossfeldiana 'Pixie'. Joumal of the American Society Horticultural Science, Alexandria, v.106, n.5, v.549-552, 1981.

LEMAIRE, F.; DARTIGUES, A.; RIVIERE, L.M. Physical and chemical characteristics of a lignocellulosis material. Acta Horticulturae, The Hague, v.238, p.9-22, 1980.

LIMA, A.M.L.P.; MINAMI, K.; MACEDO, J.C.R. Uso de vermiculita em mistura com casca de pinus e casca de arroz no enraizamento de plantas. In: CONGRESSO DA SOCIEDADE BRASILEIRA DE FLORICULTURA E PLANTAS ORNAMENTAIS, 3., Salvador, 1982. Anais... São Paulo: Instituto de Botânica; Campinas: Fundação Cargill, 1986. p.183-191.
MINAMI, K. Vermiculita e sen emprego na horticultura. Piracicaba: ESALQ, Departamento de Horticultura, 1980. 12p.

MINAMI, K. Utilizaçāo da vermiculita na floricultura e paisagismo. In: CONGRESSO DA SOCIEDADE BRASILEIRA DE FLORICULTURA E PLANTAS ORNAMENTAIS, 3., Salvador, 1982. Anais... São Paulo: Instituto de Botânica; Campinas: Fundaçāo Cargill, 1986. p.359-367.

NOLLAND, D.A.; WILLIAMS, D.J. The use of pumice and pumice-peat mixture for propagation media. Plant Propagator, v.26, n.4, p.6-7, 1980.

SALES, L.A.C. Insumo - chave dos oxissolos e vermicnlita. São Paulo: Fundação Salim Farah Maluf, 1982. 103p.

SANTOS, P.M.; FUNARI, L. M. Evapotranspiração potencial e balanço hídrico no parque do Estado, São Paulo, SP. São Paulo, 1976. Ciência e Cultura, São Paulo, v.28, n.11, p.1325-1329, 1976.

VERDONCK, O. Reviewing and evaluation of new materials used as a substrates. INTERNATIONAL SYMPOSIUM ON SUBSTRATES IN HORTICULTURE OTHER THAN SOILS IN SITU. Barcelona, 1983. Proceedings... Acta Horticultarae, The Hague, n.150, p.467-473, 1984.

Enviado para publicação em 03.05 .93

Aceito para publicação em 13.12 .93 